\title{
For local communication through Internet in the service for Good Governance in Local Decentralized Regional: Case of the Highlands of Western Cameroon
}

\author{
Dr Ing Wembe Sop Diake Hubert ${ }^{1}$, Dr Simonet Marie Antoinette ${ }^{2}$ \\ ${ }^{1}$ Faculty of Applied Economics and Management University of Douala - Cameroon \\ ${ }^{2}$ Faculty of Economics and Management, University of Dschang-Cameroon
}

\begin{abstract}
This article is part of the research theme: "Development of territories", it examines the principles governing the actions of a local call over the Internet to the implementation of good governance in the highlands of West- Cameroon. The central approach is to demonstrate how the use of the Internet to the implementation of a local improves the perception and satisfaction of the population compared to the benefits of local managers. It also demonstrates that through local internet communication can be an important managerial tool promoting good governance in the $\mathrm{CTD}^{1}$.
\end{abstract}

Keywords: Governance, Good Governance, Local Governance, Decentralization, Community decentralized territorial, Western Highlands, Local communication, Internet.

\section{INTRODUCTION}

The last four decades of the twentieth century have resurrected three major phenomena concerning the role of the state: One 1980s with the liberal revolution that questioned the role of the welfare state in favor of the state-police ". By the 1990s, there was the democratic revolution with the "east wind" with the "fall of the Berlin Wall", following the failure of the state to establish its legitimacy and to formulate policies public in line with the socio-economic needs of the population, this is what appeared for the first

\footnotetext{
${ }^{1}$ Decentralized territorial collectivities
}

time the concept of governance. The emergence of ICT, as a result of the globalization phenomenon has produced the third porous borders, opening up and deregulation of the territories. The concept of "governance" has been enriched and became one of "good governance" thus paving the way for decentralization that favored the emergence of the CTD. These CTD, become a means of local management with the objective of amélioration quality of life of its population. But even begin the exercise of roles and missions vested in it by the texts of laws that the newly elected local officials are faced with conflicts of competence in managing human resources and material. These conflicts have led to the boycott of certain CTD even seeking the dismissal of certain officials. The arguments for these boycotts are among other opaque management, non-transparency of resources, embezzlement, forgery and use of forgery, abuse of authority and especially jurisdictional disputes. All this has caused a lack of real communication. This article poses the problem of a commination aims to avoid these conflicts and attaches through the Internet as a tool to promote good governance. It is an economic and socio-political objective to: "sell the country" for investors, to create jobs and develop tourism, socio-political, to involve local people in its development of an active while enjoying the accomplishments of their leader to determine the levels of corruption. Our article is divided into three sections: Section I is that of the literature review regarding all concepts related to the notion of governance in the context of decentralization. Section II addresses the issue of good governance 
and the field research. As in Section III, it demonstrates how the implementation of a local call through internet can not only contribute to the fight against corruption but also as a management model for the improvement of different aspects of life citizens.

\section{REVIEW OF THE LITERATURE}

Governance, Local Governance, Decentralization, Local Marketing and communication are increasingly topical because of the economic and financial crisis that requires all countries to manage rationally their resources and income. Try to understand the paradigms of these concepts.

\subsection{Governance}

Governance is a polysomic term since it has a variety of definitions. Despite the multiplicity of its use, this term is related to the notion of "good governance", which relates specifically to the commonwealth in its administrative management for the general population as noted by Osiwa And Hrtc. Etymologically, governance derives from the word "govern" which comes from the Latin "gubernare", borrowed from the Greek "kubernâo" it was used in Old French as a synonym for government. Historically, this concept after the French language reflected the company management through the expression of "corporate governance" to describe a form of management of the company that was organized between the powers of owners the company and that of management. However, the definition of the concept of governance depends on the context in which it is located, thus: For $\mathrm{UNDP}^{2}$, the notion of governance for the implementation of public authority to manage the affairs of the country. Its content concerns the procedures used by institutions and citizens to defend their rights, fulfill their obligations and mediate their differences. For Westerners, it rhymes with liberal democracy and instead refers to the interactions between society and state, as well as various public and private. According to the Anglo-Saxon, this notion is close to public management (New

\footnotetext{
${ }^{2}$ United Nation Development Program
}

Public Management)).Due to these definitions, it shows a corporate governance to the private sector and political governance for the public sector which has evolved into Local Government, Regional Governance and Global Governance for the 1990s to become "good governance" according to Robert Leach, Janie Percy-Smith. Speaking of good governance, the first meaning of the Old Malian Minister Modibo Sidibe is interesting: "The concept of good governance refers to the ability of leaders to allocate resources and manage to solve development problems of any kind, of every kind and every geographical scale of a country. It is characterized by participation, transparency, accountability, rule of law, efficiency and equity. KOFI ANNAN, Former Secretary General of the United Nations, addresses in the same direction but, adding that good governance is also the means to fight against poverty. The proper management of public affairs must come to terms with efficiency, respect for public property and satisfaction of general interest. The apprehension of these two figures, it shows the key factors of good governance that are related to each other than are the responsibility of governance actors, the necessary communication, research quality and effectiveness, impacts, foresight and finally the rule of law.

- Responsibility: the various managers of public affairs are responsible for their actions vis-à-vis the population.

- The necessary communication acts posed managers must be continuously communicated to the public, open to other partners of public life, both internal and external, that for a reliable assessment.

- The quest for quality and effectiveness: public services rendered to the population must target the search for quality and achievement of the objectives of those responsible.

- Impact: the policy must aim at satisfying the public interest, regardless of the interference observed in society and which are due at the time.

- Foresight: public authorities are able to anticipate problems that arise from the available data and trends, to develop policies that reflect changing costs and expected changes (demographic, economic, environmental ...) 
- The Rule of Law: Public authorities enforce laws, regulations and codes equally and transparently.

Pushing a little further reflection the definition of good governance also reflects the policies and objectives set by international institutions such as: the World Bank and the International Monetary Fund. For the World Bank, the principles that are applied to good corporate governance should be the same for the management of public affairs; characteristics related to these principles are generally: transparency, access to information, the rule of law, accountability, public sector management, quality control, control of corruption. All these characteristics must relate to the ability of governments to manage their resources effectively, with the implementation of sound policies based on the existence of democratic control over the agents responsible for their implementation while respecting citizens. Speaking of the $\mathrm{IMF}^{3}$ : this institution works to promote good governance in the economic policies of different countries, and also provides technical assistance while making available to States in need of financial assistance, it also encourages member countries to improve greater transparency in accordance with recognized standards and codes internationally, these standards cover public administration, financial sector and businesses. As part of fiscal, monetary, and financial, states wishing to implement good governance must be submitted to the tools developed by this institution, which sometimes plays the role of policeman in particular ensuring the effective functioning of institutions responsible for monitoring public management, the effectiveness of the fight against corruption and embezzlement of public funds, and the development of various programs which aims to improve the management of public affairs. Whether the World Bank or the IMF, all agree that the practice of good governance is the basis for economic success, its actual implementation helps fight against corruption which is the logical consequence of bad governance.

\footnotetext{
${ }^{3}$ International monetary fund
}

By expanding the meaning of good governance to be within a specific context, we approach the notions of "Local Governance" and "decentralization"

\subsection{Local Governance}

To Alberic Kacou and Gregoire, local governance is a heterogeneous set of methods and practices implemented by local authorities to ensure good local management. This term was born about the year 1990 in a speech on international development made by the Bretton Woods institutions. In this speech, local governance should address local issues in administrative, economic, financial and budget. The administrative aspect relates to all processes and mechanisms of decision making. The economic aspect is that of all the steps and strategies to mobilize internal and external resources at the local level. As has the financial and budget, this is a set of policies and procedures developed to vote, execution and control of local budgets. All these aspects must consider the human resources of local government administration. Trying to implement this concept of local governance, Cameroon has opted for decentralization.

\subsection{Decentralization}

Recognizing the relevance and effectiveness of local management, the state entrusts the management of certain local affairs and local elected officials as part of good governance: what is called decentralization. As defined Miglaat, decentralization is a process that is characterized by the management of local affairs by local authorities independent of the central government as to the appointment, evaluation, or dismissal. The distribution of tasks is clear between MINATD $^{4}$, CND and the ICFTU. MINATD designing the decentralization policy and regulates its funding. The $\mathrm{NDC}^{5}$ is chaired by the Prime Minister, responsible for monitoring and evaluating its implementation, while the Interministerial Committee for Local Services is responsible for preparing and monitoring the

\footnotetext{
${ }^{4}$ Ministry of territorial administration and decentralization

${ }^{5}$ National decentralysed council
} 
transfer of skills and resources to CTD. Despite this plan into practice, decentralization is facing some difficulties in its practical phase including, insufficient financial means to own CTD, the absence of a culture of local governance and democracy at local level, inadequate quantitative and qualitative human resources at the local level, the disorganization of civil society to be an important partner of $\mathrm{CPC}^{6}$ and the inadequacy of services devolved government may accompany CTD in achieving their goals of rights. To try to solve these various problems, the strategy adopted by the State involves a pragmatic and progressive approach with principles transfer by the state of the CTD skills including: The principle of subsidiarities: the skills are transferred and exercised at the territorial level is most appropriate or as long as the people concerned (regions, municipalities, state) The principle of progressivity: This transfer of skills occurs over time and occurs in packets or in stages. The principle of complementarity: the jurisdiction is exercised concurrently by the state, regions and municipalities. The transfer means: the state provides the necessary means to CTD Powers (human, material and financial resources (local taxes and subsidies).

\subsection{Marketing}

For Pettigrew, Denis and Normand Turgeon, marketing is a management discipline that aims to determine the offers of goods, services or ideas in relation to the needs and motivation of the population. This is a set of actions that can lead an organization to anticipate, influence and needs as stated Philip Kotler. Indeed, the concept of marketing has two variants that are strategic marketing and operational marketing. Strategic marketing is an approach to analysis and reflection that allows for the match between supply and demand as mentioned in Lovelock, $\mathrm{CH}$, and Weinberg, CB It is part of the overall strategy of the company to in the long run. Its implementation in the short term operational marketing which is defined according to Jacques Lendrevie, Julien Levy and Denis Lindon as a

\footnotetext{
${ }^{6}$ Pilot commitee
}

derivative of marketing whose goal is the practical implementation of concrete actions on the ground from the general guidelines defined strategic marketing. His philosophy of logic is that unlike the short-term marketing strategy that focuses on the long term. This philosophy must take account of environmental change. Its main objective that underlines John V. Petrof, is to win new customers and retain existing customers. To achieve these objectives, according to Andreasen, $\mathrm{AR}$, it relies on direct marketing and promotion techniques. Direct marketing is a technical communication and sales promotion based on a personalized message to a target group of customers (individuals or companies) so to obtain an immediate response as stated by Theodore Levitt, he refers on the operation of a target database and differential personal contact between the provider and the client, and moreover, the use of various communication media to raise shortterm reaction of the target. As for the promotion techniques they relate to promotions, advertising and public relations whose main steps are: target identification, target setting, designing actions, and developing the marketing mix, determining the budget, performance measurement and calculation of profitability. This process uses the tools of communication such as direct mail, emailing, faxing, mailing, catalogs, trade shows and exhibitions and gadgets.

\subsection{Local Communication}

We understand by local communication, all decisions and actions of managers in the CTD, which aims to identify and disseminate information to promote adhesion of the local population. The aim is to mobilize all stakeholders in development.

\section{ISSUES AND FIELD RESEARCH}

\subsection{Problem}

The first section of our work has enabled us to understand the general concepts, it brings us to our part of the problem which must answer the following question: "How is the implementation of a policy of local communication via the Internet may it contribute to the promotion of good 
governance in the CTD to allow the objectives of decentralization are achieved? This is to demonstrate how the strengthening of democracy can be the basis of promoting local development through the communication tools particularly in the HTO which is our field of research with a strong bond with our professional activities.

\subsection{Presentation of Highlands of West Cameroon and Practical Local Governance}

\subsubsection{Presentation of Highlands of West Cameroon}

The highlands of western Cameroon are one of the ten regions; this region has an area of about $13,872 \mathrm{~km} 2$ and a population of nearly $1,982,100$ inhabitants, a density of 142.9 inhabitants per $\mathrm{km} 2$. Its climate is tropical Sudanian characterized by a dry season and rainy season. Geographically, this region is called the Highlands, since the terrain is mountainous with numerous plateaus, mountains plaines. Economically, in the highlands of western farming is practiced, including: vegetable production (potatoes, tomatoes, carrots, green beans, corn, beans ...) cash crops (coffee arabica and robusta, tea.) On the cultural and traditional region of western Cameroon is home to ethnic Bamileke and Bamum, these ethnic groups are organized into chiefdoms called "kingdoms" which most famous are those of (Bandjoun, Bafoussam, Bamougoum, Bamendjou The Bamum kingdom); Bamileke chiefdoms are specific for the cultural they have always had to present to potential visitors to the example of many traditional dances ("kougan", "Lali," "madjon") ; the whole culture that is imposed on Bamileke during a trip to the West for all visitors. Traditionally, the Bamileke chiefdom is a sociopolitical and religious entity that is individualized in a defined territory with a population that recognizes a central government headed by a Chief "King" is the feeling of solidarity group which is the unifying element of the society in which everyone is immersed; Initially, it was micro-sovereign states and beyond, these chiefdoms have become traditional structures responsible for assisting the administration in carrying out their duties. And become auxiliaries of administration, they are divided into first, second or third degree depending on the size of the number of the population or its socio-political importance.

\subsubsection{Practical Local Governance In The Highlands Of Western Cameroon}

Actual practice of local governance is expressed in HTO as in Cameroon through the CTD that are common to districts, urban communities and the urban community. The urban community led by a government delegate is the capital of the region that is Bafoussam urban municipalities in the district towns of the department (Bafoussam Mbouda Baham, Dschang, Bagangté, Bafang, Bandjoun , Foumban); rural communities in small towns and rural areas of large cities. Traditional leaders are officers of administration who are indirectly involved in the exercise of local governance. Taking specifically the case of traditional leadership in the management of good governance, trying to identify how they organize themselves to ensure that good governance in specific missions for local development. To mark their ink in the reality of good local governance structures of local governance in the highlands of Western achieve concrete marketing actions.

\subsubsection{Organization of traditional leadership}

In the highlands of western Cameroon, traditional leaders is organized in a pyramid: the leader (king) is revered and is at the top while the population at the base is (subject).The administrative organization of the village is around the head: "Fo" or "King" is a sort of monarch who traditionally concentrates all the traditional powers and is assisted by a council of notables, all residents are topics. The chief returned the land, and chair the customary court is the guardian of traditions. The village is a community with traditional territory, population, political and cultural life well organized. The landscape is different from that of the city and is usually locked. In the West, housing is grouped and the village is characterized by agro-pastoral activities. In principle, the village is divided into districts, each headed by a significant or a deputy chief or patriarch. Bamileke chiefdoms have produced over the centuries a unique cultural heritage, through a grand architecture, a diverse and original crafts, traditional dances multiple is 
any Bamileke culture that is imposed on you during a trip to the West. The Bamileke chiefdom is a religious and socio-political entity, which is individualized in a defined territory with a population that recognizes a central government headed by a chief is the feeling of solidarity group which is the backbone of society in which any individual is immersed; first micro-sovereign states, it has become traditional structures responsible for assisting the administrative agencies in carrying out their duties. As an auxiliary administration, the changing role of the head and he became the spokesman of its population with state authorities, bringing the grievances of the community and is also responsible for passing on state decisions to within the population. As part of good governance, the leader works with the local authority. Unlike the leader so the powers are hereditary, the result of local authority election or appointment. The mission of the Head is the frame of the population at the base and as such, it should promote development initiatives by coordinating economic, social and cultural village.

Whether the chief or the local authority, they provide major concern for the betterment of their people in a sense of fairness and transparency through actions such as coordinating the development committees of village are basically a non-profit associations.

\subsubsection{Community Development Committee:}

For the highlands of western Cameroon are economic entities and prosperous tourist, the son of the soil have organized to create attractive conditions through development committees endorsed by the state and managed under the gaze of the village chief as a moral authority. The rest of the population participates in the most deprived through development of their physical strength work, either by a modest financial contribution; the management committee of development requires a mechanism for transparency, fairness, satisfaction of the interest General community, the pursuit of good governance is the basis for management development committee. The business development committee, the economic is the creation of a community field in order to encourage local people to work the land, limiting the rural exodus that rural youth are victims. The
Development Committee, for his many accomplishments, is the cornerstone of improving the living conditions of local populations and a development tool in the service of local, state partner in the fight against poverty and underdevelopment by implementing good governance in its management, the committee escapes the crooked corrupt officials who leave the satisfaction of general interest to find only their own selfish interests. This committee is structured so that each participant (village head, population, elites) may play a role given the fact that it is necessary to mobilize all energies to ensure the development and well-being. The village chief is the moral authority of the structure and is assisted by the representative of the administration (subprefect) to guarantee order, security and transparency in governance. It coordinates the activities of the Development Committee; ensuring compliance with laws legalized its operation with the help of leaders and elites of the village. Committee leaders are chosen democratically to the sound management by ensuring good governance, they report to the village chief, the State, the elites, the people and sometimes to funders who may be elite, representatives of State or NGOs. These donors finance any project well put together with the economic benefits and socio-cultural as to the creation of roads, plantations, community centers, community health and social care homes as museums. The route allows the isolation of the village thus facilitating the attendance of the village by tourists, the flow of rural products to the distribution area, facilitating the stimulation of desire for the investment community. Industrial units and agribusiness allow the state to limit the rural exodus that is a scourge to both urban and rural areas. The achievements of the committee can focus in the field of agriculture, health, tourism and other in the application framework of decentralization. The construction of a community health center, creating a community field, building a museum, construction of tourist sites, are concrete examples of decentralization for good governance.

a) Agriculture, it is through the community field. The committee purchases or leases of hectares of cultivable land, he put the 
financial and material resources; recruits as young workers with whom he signed a contract on the basis of profitability, they bring their labor force: $\mathrm{c}$ is a kind of owner-occupation which part of the harvest which is the committee will be sold; income received after this sale will finance the fixed costs of the committee, as well as new community projects. The state supports this initiative through MINADER $^{7}$, especially if the support request sent to it promptly. MINAGRI ${ }^{8}$ delegated experts for technical training with concern the use of chemical fertilizers and agricultural machinery.

b) Health, the committee built a community health center. The hospital infrastructure is available to the beneficiary population. It is managed by health professionals surrounded by a few local people with skills in nursing. Health centers provide care to have the 1 st before being transferred to regional hospitals.

c) Social: building a home office and creation of a museum the home office is the space for meetings of various local associations. Recreation halls and sports area are economic activities that avoid the trouble and stress. They generate the same time revenues from rentals for special ceremonies such as weddings, parties ...... about the schools; they facilitate the education of youth, limiting illiteracy and by training human resources in expensive developing. The museum is the preservation and presentation of culture and local traditions and represents the village site of tourist landmarks. All these achievements have outstanding benefits for both the state and for local people. The main challenge of decentralization is to promote sustainable development by involving the various territories as a basis for managing their business as a great responsibility to the public. The public is invited to take initiatives locally and to invest in research appropriate solutions to local problems. The concrete content to the local management is a real administrative and financial autonomy for the management of local investments. This autonomy should promote the economic, social, educational,

\footnotetext{
${ }^{7}$ Ministry of rural development

${ }^{8}$ Ministry of agriculture
}

cultural and sporting taking into account their own realities and that of their environment. The tasks are divided between the State and Central and development actors that are the CTD, each with a specific objective: the objective of the State, rather policy is to ensure compliance with national identity, safeguarding of territorial integrity and harmonious development based on national solidarity given the imbalances of a natural community to another. As communities, they are responsible for promoting the economic, social, health, cultural and sports according to an allocation of roles established by law. This is what we call external objectives. To perform all these tasks, the CPC must seek ways to fund its investments outside the budgets allocated by the state. All these achievements require funding and a labor-intensive despite the financial contribution of each (elites and government) and other (local). To cope with these difficulties, some have turned to CPC modern techniques not only to obtain additional financial support but also to educate young people to become interested in community development. Among all these techniques, they opted for the actions of a local call which constitute an essential contribution in the implementation of good governance. To formulate some answers to our problems, several approaches in marketing science can be used according Perrien, J. et al.

\subsection{Methodological Approach}

Our methodological approach was multidimensional and iterative: Literature review, Data collection and surveys

a) Review of the literature: see section 1

b) Data collection: it was done through surveys, interviews, opinion surveys and personal observations. The surveys were conducted with local actors in the development of CTD HTO ${ }^{9}$, we traveled eight departments, each department three districts and five districts by district. The targets have different choices into account the political label of each borough and neighborhood. We interviewed not only local officials but also the adult population (1085) of both sexes over age 18

\footnotetext{
${ }^{9}$ High land of west
} 
that lived more than five years in the locality. These interviewees were divided proportionally according to gender, literacy level and broad age groups. Three age groups were considered for the selection of targets, it is the youth category (18-24 years) than adults (25-55 years) and that of the third age consists of people over 55 years. In each survey area quotas were allocated in order to meet a distribution proportional to the size of each category according to the results of General Census of Population 2006. Outside the survey, we relied on management reports, fact sheets and other documents capitalization made a direct link on good governance. These papers were full of data both quantitative and qualitative. In addition to our research, we took into account reports (2007 and 2009) self-assessment of local governance in Cameroon who provided also qualitative information on perceptions rather interesting field actors (elected officials, staff municipal, decentralized services of the State, civil society and private sector) on various aspects of local governance which are the mayor and his deputies, the city council, without the mayor and deputy of the municipal staff, civil society, decentralized departments involved at the municipal level. The following areas are assessed by state actors: Internal organization of the municipal administration, Administrative and Financial Management, Information, Participation and Gender; Benefits Administration Municipal Resource Mobilization. Each group of actors did in the first instance, its own assessment of the different areas by assigning scores. All players found themselves in a second time in plenary for the pooling of scores, which gave rise to debates and discussions very constructive after which a consensus score is selected on the basis of criteria instruments that were used to measure the performance of the municipality in each area. In addition to these reports, we took into account the results of interviews conducted by journalist's communicators in certain municipalities for collecting the assessment made by elected officials, municipal staff and people from the experience of implementation of the communication in their local community. In addition, we collected primary data. This collection was done through a free response questionnaire. As needed and support, we have used data and information from direct observation: analysis of facts and actions of local officials, decoding the speech of elected officials when radio and when touring the district ...

Following the methodological approach, data processing and analysis have enabled us to understand what will be the contribution of a local call in good governance.

\section{CONTRIBUTION OF LOCAL COMMUNICATION}

The dual objective of decentralization is that the entrenchment of democracy at the base and the improvement of living conditions of local people requires the support of a local call to improve the management of local public affairs in terms of good governance. In this section, it is question of what are the contributions of the Internet in local communication in order to sustain good local governance in the Western Highlands. From the perspective of good governance in the highlands of the west, the actions are based on the spatial planning and urban and rural on improving their image. The CPC will use the internet as a means of communication that relies on local knowledge of this environment is called positioning. The positioning elements are: the favorable geographical location (hills), the dynamism of the population, the cultural environment significantly, the associative strength (Development committee). This area's positioning improves its attractiveness in an economic and cultural. Economically, sell land, sell it is a promise of work, it is also positioning itself in the minds of potential clients that are investors and businesses. So cultural, sell land, sell it is a peaceful and enjoyable social life. So be it economic or cultural objectives remain the same: to improve the wellbeing of the population while making the most attractive areas in accordance with good governance. Positioning is the character of the land indicating its specificity. Thus, the highlands of western Cameroon could be a website that will be seen as a system of information and as a communication channel. In the sense of an information system, it will be an interconnected system linking its landscape, its organization, its 
activities and achievements. Each user can identify and transfer the information he needs by clicking on an icon. The structuring of the site will consist of tree navigation and search functions. From the perspective of local communication, this site will be considered and evaluated as a conventional media that disseminates information by integrating the tools of attractiveness as:

- Direct mail and e-mailing to convene meetings of committees of development that evaluate and monitor the effectiveness of the achievements of all stakeholders (people concerned, prefects / subprefects, traditional leaders, representatives from State and elites).

- The direct mailing to solicit financial and material support of the elites. This communication may be down when local inform the public about the progress of the projects and bottom-up, when it becomes a self-evaluation of officials from the feedback of communication engaged and to measure the impact on the state of mind, the grievances, needs and opinions of the population. It appears that the contribution of the Internet for local communication is a tool for quality improvement of municipal management by an intrusion of a managerial management that will attract businesses, tourists but also investors in highlands west to boost its economy and create wealth, not to mention the impact in terms of image on its cultural richness. As the implementation of communication enhances the perception of local people on the benefits of the municipal administration, as it induces a positive change of behavior of local councilors and municipal staff, particularly in the exercise by them of different types of local governance (in this case: political, administrative governance, economic governance, financial governance and budget). Moreover, these elites and investors through this site will immediately have local information on local realities in order to control any action appropriate achievements.

\section{CONCLUSION}

After putting forward the review of the literature regarding all concepts related to the notion of governance in the context of decentralization, addresses the issue of good governance and the field research, we demonstrate how the setting implementation of a local call through the internet can not only contribute to the fight against corruption but also as a management model for the improvement of different aspects of people's lives that was the subject of this communication article.la Local via the Internet may therefore give greater clarity to strategic choices and communal action, effective flow of information within the municipal team (local councilors, municipal officials), raising awareness among populations communal services and their services, mobilize people and any other development, ensuring the strengthening of citizenship (to get people out of their common status as ordinary residents the status of citizens of the town).

\section{REFERENCES}

[1] Busha, C., and Harter, S.P., Research methods in librarianship. Techniques and interpretation, New York, Academic Press, 1980.

[2] Chapitre 3: Survey research in librarianship

[3] Gregoire (Luc-Joël) et al.2008. L'Afrique et les défis de la Gouvernance, Maisonneuve § Louise Paris 790P.

[4] Kacou (Alberic) Et Gregoire (Luc-Joël) 2008 ( La dimension centrale de la gouvernance et les priorités pour l'atteinte des Objectifs du Millénaire pour le Développement).

[5] Kotler, P, Marketing for nonprofit organizations, Englewood Cliffs (N.J.), Prentice-Hall, 2nd ed., 1982. Chapitre 6: Marketing information and research

[6] John Kenneth Galbraith : Le nouvel Etat industriel 1967

[7] John V. Petrof, Comportement du consommateur et marketing, Les presses de l'université de Laval, 5e édition 2002, p451 
[8] Lovelock, C.H, and Weinberg, C.B., Marketing for public and nonprofit managers, New York, Wiley, 1984. Chapitre 6: Marketing research

[9] Miglaat, juin 2009, Ponader, Politique Nationale de Décentralisation et de Déconcentration, document cadre politique, $85 \mathrm{P}$.

[10] Osiwa Et Cird (avril 2004): Guide d'exercice d'une bonne gouvernance locale, Presses de l'Imprimerie CACIBénin Cotonou 179P.

[11] Perrien, J., et al. Recherche en marketing: méthodes et décisions, Chicoutimi, Gaëtan Morin éditeur
(diff.Paris: Editions Eska S.A.R.L.), 1983

[12] Pettigrew, Denis et Normand, Turgeon. Marketing, Éditions Chenelière Éducation: Montréal. 2008, page 134

[13] Philip Kotler, Marketing management, 11e édition, 2003

[14] Sidibe (Modibo 2008) «L'expérience en matière de bonne gouvernance »

[15] Site du Groupe sur la gouvernance de la WBI (World Bank Institut)

[16] Theodore Lewitt, Creativity Is Not Enough, Harvard Business Review, 1963

[17] World Bank policy Research working paper $\mathrm{N}^{\circ} 2195$ PDF 42P 